\title{
Sequential administration of XELOX and XELIRI is effective, feasible and well tolerated by patients with metastatic colorectal cancer
}

\author{
TARO FUKUI, KOICHI SUZUKI, KOSUKE ICHIDA, YUJI TAKAYAMA, NAO KAKIZAWA, \\ YUTA MUTO, FUMI HASEGAWA, FUMIAKI WATANABE, RINA KIKUGAWA, MASAAKI SAITO, \\ SHINGO TSUJINAKA, YASUYUKI MIYAKURA and TOSHIKI RIKIYAMA
}

Department of Surgery, Saitama Medical Center, Jichi Medical University, Saitama, Saitama 330-8503, Japan

Received March 9, 2016; Accepted March 3, 2017

DOI: $10.3892 / \mathrm{ol} .2017 .6100$

\begin{abstract}
Sequential administration of the chemotherapy regimes capecitabine and oxaliplatin (XELOX) and capecitabine and irinotecan (XELIRI) in the first- to second-line treatment setting would allow patients to be managed more easily in an outpatient unit. However, a small number of studies have raised concerns of cumulative adverse events as a consequence of the continuous use of capecitabine. To investigate this, the present study conducted a retrospective review of 81 consecutive metastatic colorectal cancer (mCRC) patients treated with the oxaliplatin, fluorouracil and leucovorin-irinotecan, fluorouracil and leucovorin (FOLFOX-FOFIRI/F-F) regimen $(n=40)$ or the XELOX-XELIRI $(X-X)$ regimen $(n=41)$ in first- to second-line chemotherapy in Saitama Medical Center between 2006 and 2012. The disease control rate (DCR), the progression free survival (PFS), the overall survival (OS) and the time to failure of strategy (TFS) from first to second-line chemotherapy, as well as adverse events, were assessed and compared between patients receiving X-X or F-F. A total of 10 and 20 patients were additionally treated with bevacizumab in the F-F and X-X regimens, respectively, during first or second-line chemotherapy. There was no significant difference in DCR and the median PFS between the two regimens for first or second-line chemotherapy. There was no significant difference in the median OS and TFS between the two regimens $(\mathrm{OS}=24.5$ and TFS $=14$ months in the F-F vs. 23.2 and 12.0 months in the X-X). Regarding adverse events, $45.0 \%$ of patients (18/40) exhibited grade 3-4 neutropenia throughout treatment with F-F. Whilst, $15.0 \%$ of patients (6/41) exhibited grade 3 hypertension throughout treatment with $\mathrm{X}-\mathrm{X}$, which
\end{abstract}

Correspondence to: Dr Koichi Suzuki, Department of Surgery, Saitama Medical Center, Jichi Medical University, 1-847 Amanuma-cho, Omiya, Saitama, Saitama 330-8503, Japan E-mail:ksuzbnhm@yahoo.co.jp

Key words: sequential administration, XELOX, XELIRI, bevacizumab, metastatic colorectal cancer was effectively controlled by a single antihypertensive drug. The results show that sequential administration of $\mathrm{X}-\mathrm{X}$ is as effective and feasible as F-F treatment, while additionally reducing the frequency of infusion visits and eliminating the need for a central venous access device or home infusion pump, thereby offering a more convenient treatment option to patients with $\mathrm{mCRC}$.

\section{Introduction}

The National Comprehensive Cancer Network guidelines for the management of colorectal cancer recommend the initial treatment of metastatic colorectal cancer (mCRC) with oxaliplatin, fluorouracil and leucovorin (FOLFOX) or irinotecan (CPT-11), fluorouracil and leucovorin (FOLFIRI) in combination with bevacizumab (1). This is followed by second-line treatment with the regimen not selected for initial treatment in the event of disease progression (1).

Alternatives to FOLFOX and FOLFIRI include the combination of oral fluorouracil and a venous drip infusion of oxaliplatin (administered as XELOX, the combination of capecitabine and oxaliplatin) or CPT-11 (administered as XELIRI, the combination of capecitabine and irinotecan), which are widely used for patients with $\mathrm{mCRC}$, as first-line therapy (2-4). XELOX and XELIRI regimens in combination with bevacizumab typically have the benefit of not needing a central venous access device (CVAD) or a home infusion pump, and require less frequent outpatient visits. In a first-line setting, the XELIRI-bevacizumab regimen has been demonstrated to exhibit efficacy equivalent to FOLFIRI or XELOX in combination with bevacizumab, according to the ACCORD 13 study (3) and AIO trial 0604 (4). However, the efficacy of XELIRI-bevacizumab for second-line therapy remains largely unknown.

In a Phase III trial (ML18147), the tri-weekly XELIRIbevacizumab regimen, as used in AIO trial 0604, was selected for $12 \%$ of patients, while a CPT-11-based regimen was selected for $\sim 35 \%$ of patients as second-line therapy (5). This indicates that XELIRI-bevacizumab is recognized as a viable treatment option alongside FOLFOX-bevacizumab and FOLFIRI-bevacizumab for European patients. In Japan, 
a Phase I/II study (the BIX study) was conducted to evaluate the benefits of the dosage regimen used in the AIO trial 0604 in patients with $\mathrm{mCRC}$ who had previously been treated with oxaliplatin and bevacizumab. The BIX study showed that XELIRI-bevacizumab was safe and effective in Japanese patients (6).

Sequential administration of XELOX and XELIRI in combination with bevacizumab in a first- to second-line setting would allow patients to be managed more easily in an outpatient unit. However, only a small number of studies have considered the benefits of this strategy (7), and concerns regarding cumulative adverse events as a consequence of continuous use of capecitabine remain (8).

In the present study, the efficacy and feasibility of sequential administration of XELOX and XELIRI (X-X) in combination with bevacizumab in a first- to second-line setting was evaluted, and compared with the FOLFOX-FOLFIRI (F-F) regimen.

\section{Materials and methods}

Patients and treatments. Bevacizumab and capecitabine were purchased from Chugai Pharmaceutical Co., Ltd. (Tokyo, Japan); folinic acid from Pfizer Japan, Inc. (Tokyo, Japan); fluorouracil (5-FU) from Kyowa Hakko Kirin Co., Ltd. (Tokyo, Japan) and oxaliplatin and irinotecan (CPT-11) from Yakult Honsha Co., Ltd. (Tokyo, Japan).

A total of 81 consecutive patients with $\mathrm{mCRC}$, all of Asian descent, were recruited to the study from at the Saitama Medical Center, Jichi Medical University (Saitama, Japan) between January 2006 and December 2012. The patients were treated with the F-F regimen, with or without bevacizumab $(n=40)$ or the $X-X$ regimen with or without bevacizumab $(n=41)$ as first- to second-line chemotherapy.

Individuals described as receiving the FOLFOX regimen received either a FOLFOX4 or mFOLFOX6 regimen. The FOLFOX4 regimen consisted of folinic acid $\left(200 \mathrm{mg} / \mathrm{m}^{2}\right)$, fluorouracil (5-FU; $400 \mathrm{mg} / \mathrm{m}^{2}$ ) followed by $22 \mathrm{~h}$ of continuous infusion with 5 -FU $600 \mathrm{mg} / \mathrm{m}^{2}$ for 2 consecutive days every 2 weeks, with a 2 -h infusion of oxaliplatin $\left(85 \mathrm{mg} / \mathrm{m}^{2}\right)$ on day 1 . The mFOLFOX6 regimen consisted of folinic acid $\left(200 \mathrm{mg} / \mathrm{m}^{2}\right)$, fluorouracil $\left(5-\mathrm{FU} ; 400 \mathrm{mg} / \mathrm{m}^{2}\right)$ and oxaliplatin $\left(85 \mathrm{mg} / \mathrm{m}^{2}\right)$ on day 1 , followed by $46 \mathrm{~h}$ of continuous infusion with 5 -FU $2,400 \mathrm{mg} / \mathrm{m}^{2}$ on days 1 and 2 , with or without bevacizumab $(5 \mathrm{mg} / \mathrm{kg})$ on day 1 and every 14 th day. The FOLFIRI regimen included folinic acid $\left(200 \mathrm{mg} / \mathrm{m}^{2}\right)$, 5 -FU $\left(400 \mathrm{mg} / \mathrm{m}^{2}\right)$ and CPT-11 $\left(150 \mathrm{mg} / \mathrm{m}^{2}\right)$ on day 1 , followed by $46 \mathrm{~h}$ of continuous infusion with $5-\mathrm{FU}\left(2,400 \mathrm{mg} / \mathrm{m}^{2}\right)$ on days 1 and 2, with or without bevacizumab depending on the patient $(5 \mathrm{mg} / \mathrm{kg})$ on day 1 and $\mathrm{q} 14 \mathrm{~d}$.

As a first-line chemotherapy, the XELOX regimen consisted of capecitabine $\left(1,600 \mathrm{mg} / \mathrm{m}^{2}\right.$ for patients aged $\geq 65$ years or $2,000 \mathrm{mg} / \mathrm{m}^{2}$ for patients aged $<65$ years) on days $1-15$ and oxaliplatin $\left(130 \mathrm{mg} / \mathrm{m}^{2}\right)$ on day 1 , with or without bevacizumab $(7.5 \mathrm{mg} / \mathrm{kg})$ depending on the patient, on day 1 and q21d.

As a second-line chemotherapy, the XELIRI regimen consisted of CPT-11 $\left(200 \mathrm{mg} / \mathrm{m}^{2}\right)$ on day 1 in combination with oral capecitabine $\left(1,600 \mathrm{mg} / \mathrm{m}^{2}\right.$ for patients aged $\geq 65$ years or $2,000 \mathrm{mg} / \mathrm{m}^{2}$ for patients aged $<65$ years) on days $1-15$, with or without bevacizumab depending on the patient $(7.5 \mathrm{mg} / \mathrm{kg})$
Table I. Patient characteristics.

\begin{tabular}{|c|c|c|c|}
\hline Characteristic & $\begin{array}{c}F-F \\
(n=40)\end{array}$ & $\begin{array}{c}X-X \\
(n=41)\end{array}$ & P-value \\
\hline $\begin{array}{l}\text { Age, years } \\
\text { [median (range)] }\end{array}$ & $\begin{array}{c}66 \\
(40-86)\end{array}$ & $\begin{array}{c}66 \\
(37-85)\end{array}$ & $0.48^{\mathrm{a}}$ \\
\hline Gender, $\mathrm{n}$ & & & $0.58^{\mathrm{b}}$ \\
\hline Male & 27 & 30 & \\
\hline Female & 13 & 11 & \\
\hline Primary tumor site, $\mathrm{n}$ & & & $0.20^{\mathrm{b}}$ \\
\hline Colon & 28 & 23 & \\
\hline Rectum & 12 & 18 & \\
\hline Primary lesion, $\mathrm{n}$ & & & $0.71^{\mathrm{b}}$ \\
\hline Resected & 38 & 36 & \\
\hline Remained & 2 & 5 & \\
\hline Bevacizumab, $\mathrm{n}$ & & & $0.03^{\mathrm{b}}$ \\
\hline Included & 10 & 20 & \\
\hline not included & 30 & 21 & \\
\hline Metastatic site, $\mathrm{n}$ & & & $0.02^{\mathrm{b}}$ \\
\hline Liver & $19^{c}$ & 19 & \\
\hline Lung & 4 & 6 & \\
\hline Lymph nodes & 4 & 5 & \\
\hline Peritoneum & 11 & 2 & \\
\hline Other & 2 & 9 & \\
\hline
\end{tabular}

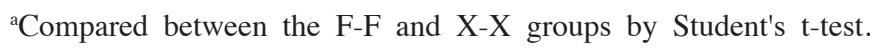
${ }^{\mathrm{b}}$ Compared between the F-F and X-X groups by $\chi^{2}$ test. ${ }^{\mathrm{c} O n e}$ patient underwent conversion hepatic resection. F-F, FOLFOX-FOFIRI; $\mathrm{X}-\mathrm{X}, \mathrm{XELOX}$-XELIRI.

on day 1 and q21d. The gradual dose reduction from first-line chemotherapy was also applied to second-line chemotherapy. Schemas of the treatment schedule for the F-F and X-X regimens are included in Fig. 1.

Efficacy and safety assessment. Progression free survival (PFS) rates, overall survival (OS) rates and adverse events were assessed and compared between the F-F and X-X regimens. In addition, the time to failure of strategy (TFS), which was the period from the start of first-line chemotherapy to the end of second-line chemotherapy, was assessed. Lesions were evaluated every 3-4 cycles of chemotherapy by a computed tomography scan. Tumor response and progression were assessed as complete response (CR), partial response (PR), stable disease (SD) or progressive disease (PD) according to the Response Evaluation Criteria for Solid Tumors (9). Adverse events were graded as 0-4 according to the Common Terminology Criteria for Adverse Events, version 3.0 (10). Treatment was continued till disease progression, unacceptable toxicity (grade 3/4), deterioration of Eastern Cooperative Oncology Group performance status (11) to $>2$, or withdrawal of patient consent. The present study was approved by the Research Ethics Committee of Jichi Medical University. Written informed consent was obtained from all patients prior to chemotherapy, according to institutional guidelines. 


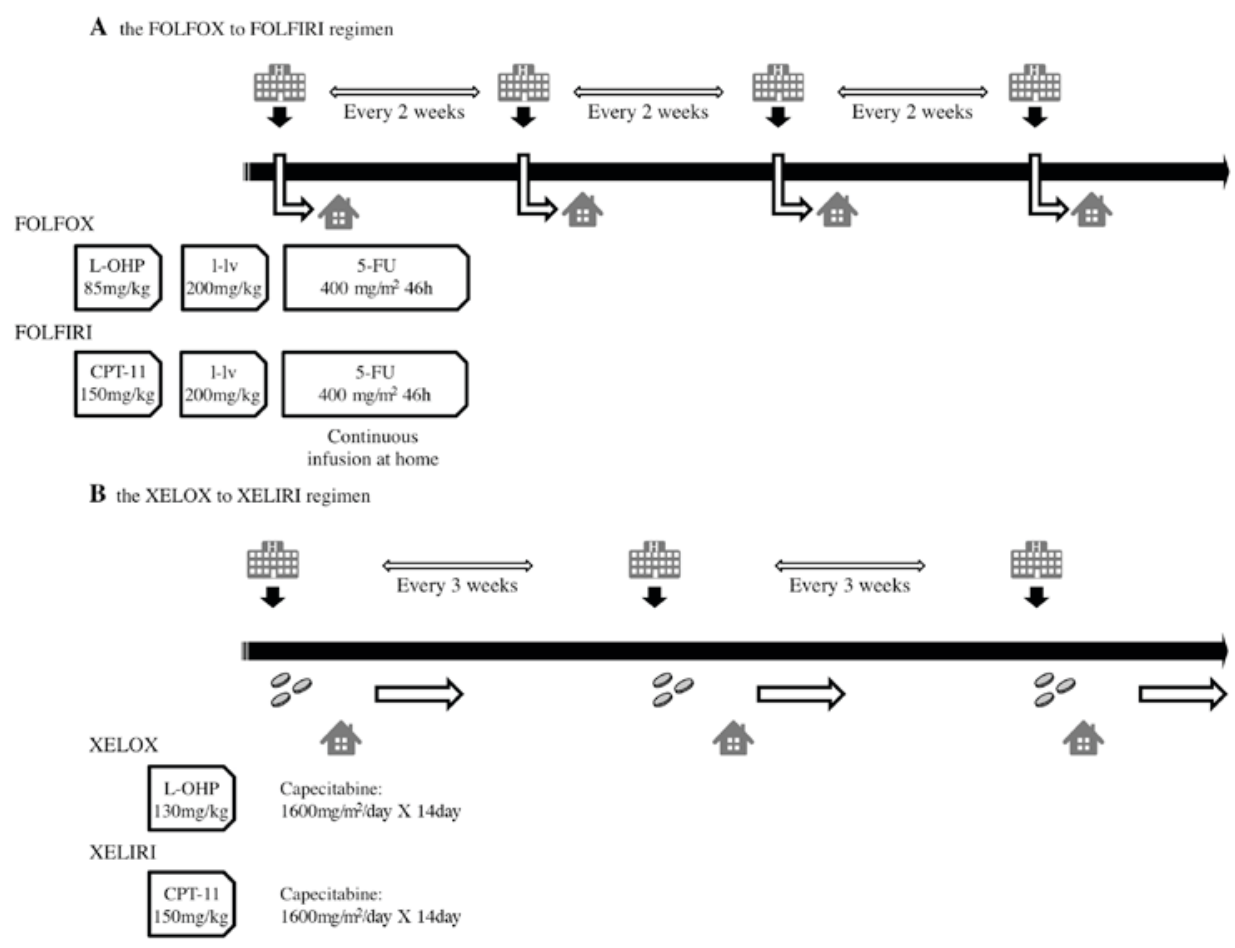

Figure 1. Schema of the treatment schedules for FOLFOX-FOFIRI and XELOX-XELIRI regimens. (A) The FOLFOX-FOFIRI regimen requires a central venous access device, the use of a home infusion pump and bi-weekly visits to the hospital. (B) The XELOX-XELIRI regimen has the comparative advantage of reducing the frequency of infusion visits and eliminating the need for a central venous access device or home infusion pump.

Table II. Relative dose intensity.

\begin{tabular}{|c|c|c|c|c|c|c|c|c|}
\hline \multirow[b]{3}{*}{ Treatment } & \multicolumn{4}{|c|}{$\mathrm{F}-\mathrm{F}, \%(\mathrm{n}=40)$} & \multicolumn{4}{|c|}{$\mathrm{X}-\mathrm{X}, \%(\mathrm{n}=41)$} \\
\hline & \multicolumn{2}{|c|}{ FOLFOX } & \multicolumn{2}{|c|}{ FOLFIRI } & \multicolumn{2}{|c|}{ XELOX } & \multicolumn{2}{|c|}{ XELIRI } \\
\hline & $5-\mathrm{FU}$ & L-OHP & $5-\mathrm{FU}$ & CPT-11 & Cap & L-OHP & Cap & CPT-11 \\
\hline Relative dose intensity & 92.3 & 92.2 & 93.8 & 90.2 & 90.1 & 94.2 & 85.3 & 86.4 \\
\hline Full dose & 65.8 & 65.8 & 70.0 & 57.4 & 73.9 & 74.3 & 43.0 & 58.4 \\
\hline
\end{tabular}

F-F, FOLFOX-FOFIRI; X-X, XELOX-XELIRI; 5-FU, 5-fluorouracil; L-OHP, oxaliplatin; CPT-11, irinotecan; Cap, capecitabine.

Statistical analysis. A $\chi^{2}$ test was used to assess the association between two categorical variables. Continuous comparisons between two groups were performed using a Student's t-test for normally distributed data, and the non-parametric Mann-Whitney $U$ test for data that were not normally distributed. $\mathrm{P}<0.05$ was considered to indicate a statistically significant difference. Values are shown as the mean \pm standard deviation. PFS, OS and TFS data are plotted as Kaplan-Meier curves, and the differences among groups were compared with the log-rank test. STAT View Version 5.0.1 (SAS Institute Inc., $\mathrm{NC}$, USA) was used to perform all analyses.

\section{Results}

Patient characteristics. Patient characteristics are summarized in Table I. In total, 40 patients received the F-F regimen and 41 patients underwent the X-X regimen. In the F-F group, 10 patients (25\%) were treated with bevacizumab during first or second line chemotherapy, whereas 20 patients (49\%) received bevacizumab in the $\mathrm{X}$-X group. There was a significant diffe rence in the likelihood of bevacizumab administration between the two groups $(\mathrm{P}=0.03)$; however, there were no significant differences in median age, sex, primary tumor site, or the likelihood of resection of the primary tumor $(\mathrm{P}=0.48,0.58$, 0.20 and 0.25 , respectively). There was a significant difference in the metastatic site between the two groups $(\mathrm{P}=0.02)$. The median follow-up was 16.1 months (range, 5.1-39.0) in the F-F regimen and 19.9 months (range, 4.0-46.6) in the $\mathrm{X}$-X regimen.

Relative dose intensity. During first-line treatment, the mean relative dose intensities were $92.3 \%$ for 5 -FU and $92.2 \%$ for oxaliplatin in the F-F group, and $90.1 \%$ for capecitabine and $94.2 \%$ for oxaliplatin in the $\mathrm{X}$-X group. There were no significant differences in relative dose intensity between groups (Table II).

During second-line treatment, the average relative dose intensities were $93.8 \%$ for $5-\mathrm{FU}$ and $90.2 \%$ for CPT-11 in 


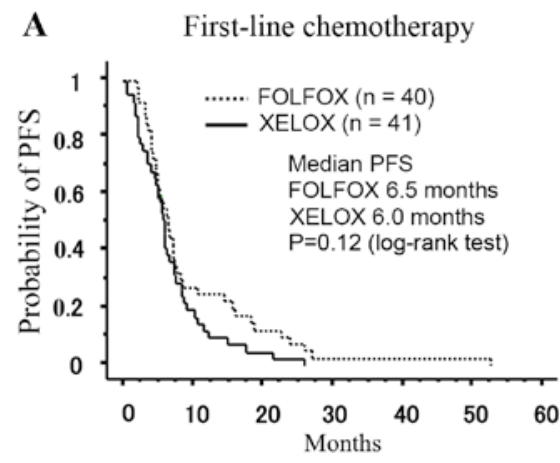

C

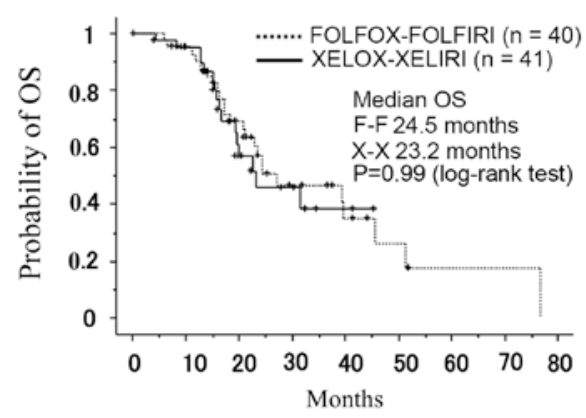

B

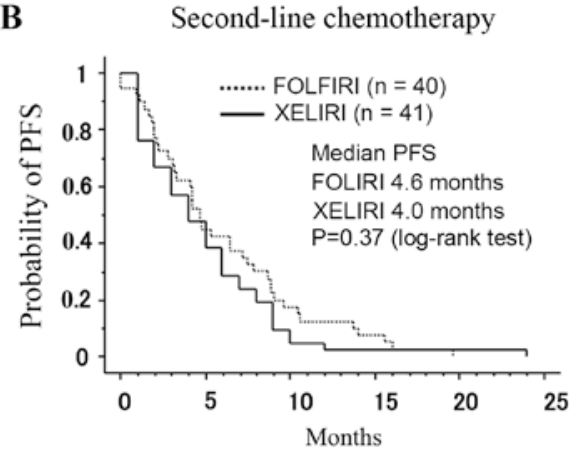

D

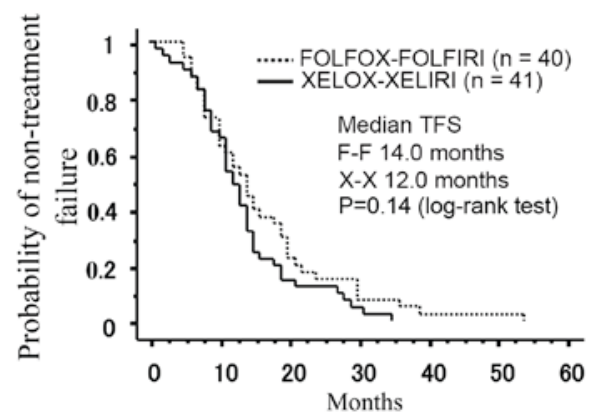

Figure 2. Kaplan-Meier survival curves. (A) Comparison of PFS time for patients treated with FOLFOX or XELOX as a first-line chemotherapy. (B) Comparison of PFS time for patients treated with FOLFIRI or XELIRI as a second-line chemotherapy. (C) Comparison of OS time (the period from the start of first-line chemotherapy, to mortality due to any cause) in patients treated by the F-F and X-X regimens. (D) Comparison of TFS time (the period from the start of first-line chemotherapy to the end of second-line chemotherapy) in patients treated by the F-F and X-X regimens. PFS, progression-free survival; OS, overall survival; TFS, time to failure of strategy.

the F-F group, and $85.3 \%$ for capecitabine and $86.4 \%$ for CTP-11 in the X-X group. There were no significant differences in relative dose intensity between groups. The rate of the full dose of capecitabine in the XELIRI regimen being administered was $43.0 \%$, which is relatively low; this was due to a reduction of the capecitabine dose in order to decrease the incidence of adverse events for some patients during first-line treatment being carried over to second-line treatment, resulting in a number of patients then receiving $80 \%$ or $65 \%$ of $1,600 \mathrm{mg} / \mathrm{m}^{2}$ of capecitabine as the initial dose in second-line treatment.

Efficacy. During first-line treatment, DCR was $85.0 \%$ for the FOLFOX regimen and $58.5 \%$ for the XELOX regimen. The median PFS was 6.5 months for the FOLFOX regimen and 6.0 months for the XELOX regimen ( $\mathrm{P}=0.12$, Fig. $2 \mathrm{~A})$. During second-line treatment, DCR was $50.0 \%$ for the FOLFIRI regimen and $41.4 \%$ for the XELIRI regimen. The median PFS was 4.6 months for the FOLFIRI regimen and 4.0 months for the XELIRI regimen ( $\mathrm{P}=0.37$, Fig. $2 \mathrm{~B})$, which was not significantly different. The median OS was 24.5 months in the F-F regimen and 23.2 months in the $\mathrm{X}-\mathrm{X}$ regimen $(\mathrm{P}=0.99$, Fig. 2C), which was not significantly different. The median TFS was 14.0 months in the F-F regimen and 12.0 months in the $\mathrm{X}-\mathrm{X}$ regimen $(\mathrm{P}=0.14$, Fig. $2 \mathrm{D})$. The relative dose intensity was low in the XELIRI regimen, but this did not appear to affect median PFS, OS and TFS. To eliminate the potential bias introduced by the number of patients receiving bevacizumab in each group when comparing the $\mathrm{X}-\mathrm{X}$ and F-F regimens, subgroup analysis was performed using patients who did not receive bevacizumab. There was no difference in the median OS rate between these subgroups $(\mathrm{P}=0.27$; data not shown).

Feasibility. Regarding the most frequently reported grade 3-4 adverse events, the incidence of severe (grade $\geq 3$ ) neutropenia was $47.5 \%$ in the F-F group, and $24.4 \%$ in the X-X group $(\mathrm{P}=0.030$, Table III). Febrile neutropenia was detected in 1 case in the F-F group and 3 cases in the $\mathrm{X}-\mathrm{X}$ group. The incidence of severe (grade $\geq 3$ ) hypertension was $0 \%$ in the F-F group, and $14.6 \%$ in the $\mathrm{X}-\mathrm{X}$ group $(\mathrm{P}=0.012$, Table III). All hypertensive patients were successfully treated with a single antihypertensive drug. No treatment-associated mortality was reported.

Subsequent therapy. There was no significant difference in subsequent therapies between groups (Table IV).

\section{Discussion}

The findings of the present study have demonstrated that sequential administration of $\mathrm{X}-\mathrm{X}$ is as effective and feasible as F-F, with the additional advantage of reducing the frequency of infusion visits, and eliminating the need for a CVAD or home infusion pump.

Regarding treatment efficacy, there was no significant difference between the XELOX and FOLFOX regimens in first-line therapy (6.5 vs. 6.0 months, $\mathrm{P}=0.12$ ), which is consistent with previous reports (12) or the XELIRI and FOLFIRI in second line therapy, (4.6 vs. 4.0 months, $\mathrm{P}=0.37$ ). In previous clinical trials, FOLFIRI2 (continuous infusion of 5-FU, followed by CPT-11) had a median PFS of 4.1 months (13), and 
Table III. Adverse events.

\begin{tabular}{|c|c|c|c|c|c|}
\hline \multirow[b]{2}{*}{ Symptom } & \multicolumn{2}{|c|}{$\mathrm{F}-\mathrm{F}(\mathrm{n}=40)$} & \multicolumn{2}{|c|}{$X-X(n=41)$} & \multirow{2}{*}{$\frac{P \text {-value }}{(\geq \mathrm{G} 3)}$} \\
\hline & All, $\%$ & $\geq \mathrm{G} 3, \%$ & All, \% & $\geq \mathrm{G} 3, \%$ & \\
\hline Leucopenia & 85.0 & 27.5 & 78.0 & 19.5 & 0.40 \\
\hline Neutropenia & 77.5 & 47.5 & 65.9 & 24.4 & 0.03 \\
\hline Anemia & 67.5 & 7.50 & 65.9 & 7.30 & 0.98 \\
\hline Thrombocytopenia & 47.5 & 2.50 & 51.2 & 2.40 & 0.99 \\
\hline Liver dysfunction & 92.5 & 7.50 & 85.4 & 2.40 & 0.29 \\
\hline Renal dysfunction & 27.5 & 2.50 & 17.1 & 2.40 & 0.99 \\
\hline Diarrhea & 52.5 & 5.00 & 58.5 & 2.40 & 0.54 \\
\hline Constipation & 50.0 & 0 & 39.0 & 2.40 & 0.32 \\
\hline Nausea & 72.5 & 2.50 & 63.4 & 0 & 0.31 \\
\hline Vomiting & 32.5 & 2.50 & 39.0 & 2.40 & 0.99 \\
\hline Fatigue & 52.5 & 2.50 & 61.0 & 4.90 & 0.57 \\
\hline Stomatitis & 60.0 & 2.50 & 61.0 & 2.40 & 0.99 \\
\hline Neuropathy & 87.5 & 2.50 & 92.7 & 4.90 & 0.58 \\
\hline HFS & 30.0 & 0 & 53.7 & 0 & 1.00 \\
\hline Hypertension & 2.50 & 0 & 34.1 & 14.60 & 0.01 \\
\hline
\end{tabular}

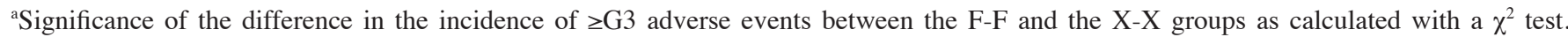
F-F, FOLFOX-FOFIRI; X-X, XELOX-XELIRI; G3, grade 3 based on Common Terminology Criteria for Adverse Events; HFS, hand-food syndrome.

Table IV. Subsequent therapies.

\begin{tabular}{lcc}
\hline $\begin{array}{l}\text { Therapy } \\
\text { method }\end{array}$ & $\begin{array}{c}\mathrm{F}-\mathrm{F}, \mathrm{n} \\
(\mathrm{n}=40)\end{array}$ & $\begin{array}{c}\mathrm{X}-\mathrm{X}, \mathrm{n} \\
(\mathrm{n}=41)\end{array}$ \\
\hline $\begin{array}{l}\text { Anti-EGFR antibody } \\
(\mathrm{C}-\mathrm{mab}+\mathrm{CPT}-11 / \mathrm{C}-\mathrm{mab}\end{array}$ & $\begin{array}{c}14 \\
(6 / 2 / 6)\end{array}$ & $\begin{array}{c}12 \\
(1 / 0 / 12)\end{array}$ \\
$\begin{array}{l}\text { only/P-mab) } \\
\begin{array}{l}\text { Other therapies } \\
\text { Best supportive care }\end{array}\end{array}$ & 2 & 3 \\
$\begin{array}{l}\text { Unknown } \\
\text { Unknow }\end{array}$ & 23 & 26 \\
\end{tabular}

${ }^{a}$ Two patients in the F-F group were additionally treated with FOLFOX6 and bevacizumab with FOLFIRI, respectively. Three patients in the $\mathrm{X}-\mathrm{X}$ group were additionally treated with Xeloda, an additional bevacizumab with XELIRI and XELIRI, respectively. F-F, FOLFOX-FOFIRI; X-X, XELOX-XELIRI; EGFR, epidermal growth hormone receptor; C-mab, cetuximab; CPT-11, irinotecan; P-mab, panitumumab.

FOLFIRI3 (continuous infusion of 5-FU with CPT-11) had a median PFS of 4.1 months (14), which is in accordance with the present study. It was previously reported in a non-randomized study that sequential administration of X-X (without bevacizumab) resulted in a median PFS of 7.0 and 2.0 months in first- and second-line chemotherapy, respectively (9). The time to second progression (described as TFS in the present study) was 10 months, compared with 12 months in the present study.

In the present study, a significant difference in the number of patients receiving bevacizumab between the F-F and X-X groups was identified, with 10 and 20 patients receiving bevacizumab in the F-F and X-X groups, respectively. However, as identified in the subgroup analysis, there was no difference in median OS rate between patients who did and did not receive bevacizumab, which suggests that $\mathrm{X}-\mathrm{X}$ is as effective as the F-F regimen without considering bevacizumab.

According to a systematic review (Phase II) bevacizumab in combination with FOLFIRI prolongs the median PFS to 8.3 months compared with FOLFIRI alone, in the second-line setting (15). XELIRI in combination with bevacizumab was associated with a median PFS of 8.3 months in the second-line setting in the BIX study (6), which is considerably longer than in the present study, where the median PFS was 4.6 months (where $49 \%$ of patients were treated with bevacizumab). However, we previously reported a median PFS of 7.2 months when all patients were treated with XELIRI with bevacizumab in the second-line setting (16).

The BIX study (6) showed that the most common Grade 3-4 adverse events were nausea (5.9\%), diarrhea (5.9\%), fatigue $(2.9 \%)$ and neutropenia $(8.8 \%)$. The efficacy analysis revealed an overall response rate of $17.6 \%$ and a PFS time of 8.3 months (6), consistent with the data of the present study. Due to the dose modification of capecitabine during first-line treatment, no cumulative adverse events were observed as a consequence of the continued use of capecitabine in the present study. Severe hypertension ( $\geq$ grade 3 ) was seen in $14.6 \%$ of patients in the X-X group; however, all of the hypertensive patients were successfully treated with a single antihypertensive drug. These findings suggest that $\mathrm{X}-\mathrm{X}$ plus bevacizumab is a safe and effective treatment for patients with $\mathrm{mCRC}$ of Asian descent.

Unlike FOLFOX or FOLFIRI, the $\mathrm{X}-\mathrm{X}$ regimen does not require a central venous access device (CVAD), which 
itself may cause complications. Indeed, CVAD-associated complications are possible including pain, hematoma and hemorrhage, site infection and catheter thrombosis, although no such complications occurred in the present study. Another possible complication associated with CVAD is pump malfunction, which may cause accelerated drug delivery during contentious infusion of 5-FU and increase the risk of grade $3 / 4$ neutropenia (17).

The tri-weekly $\mathrm{X}-\mathrm{X}$ regimen is more convenient in terms of administration and increases the time for work and other activities compared with FOLFOX-6 (18). Sequential use of oral fluoropyrimidines may be more convenient for patients with mCRC. In addition, it is reported that XELOX significantly decreased the direct treatment costs of patients with mCRC compared with the cost of FOLFOX-6 (19). XELOX or XELIRI can be introduced in an outpatient setting as the treatment can be administered in a comparatively short time, limiting the use of hospital resources as patients would not need to be admitted for chemotherapy.

In conclusion, the present results should be interpreted within the context of the study limitations; the study was retrospective and only considered members from specific treatment groups. Further studies, including multinational randomized phase III studies, are required to draw definitive conclusions. However, based on the results of the present study, the administration of $\mathrm{X}-\mathrm{X}$ has been demonstrated to be as effective and feasible as F-F, with the advantage of reducing the frequency of infusion visits with no need for a CVAD or home infusion pump.

\section{Acknowledgements}

This work was supported in part by a grant-in-aid of the post graduate students from Jichi Medical University, a grant-in-aid from the Ministry of Education, Culture, Sports, Science and Technology (grant no. JP16K10514), and the JKA Foundation through its promotion funds from Keirin Racing (grant no. 27-1-068).

\section{References}

1. Tournigand C, André T, Achille E, Lledo G, Flesh M, Mery-Mignard D, Quinaux E, Couteau C, Buyse M, Ganem G, et al: FOLFIRI followed by FOLFOX6 or the reverse sequence in advanced colorectal cancer: A randomized GERCOR study. J Clin Oncol 22: 229-237, 2004.

2. Arkenau HT, Arnold D, Cassidy J, Diaz-Rubio E, Douillard JY, Hochster H, Martoni A, Grothey A, Hinke A, Schmiegel W, et al: Efficacy of oxaliplatin plus capecitabine or infusional fluorouracil/leucovorin in patients with metastatic colorectal cancer: A pooled analysis of randomized trials. J Clin Oncol 26: 5910-5917, 2008.

3. Ducreux M, Adenis A, Pignon JP, François E, Chauffert B, Ichanté JL, Boucher E, Ychou M, Pierga JY, Montoto-Grillot C and Conroy T: Efficacy and safety of bevacizumab-based combination regimens in patients with previously untreated metastatic colorectal cancer: Final results from a randomised phase II study of bevacizumab plus 5-fluorouracil, leucovorin plus irinotecan versus bevacizumab plus capecitabine plus irinotecan (FNCLCC ACCORD 13/0503 study). Eur J Cancer 49: 1236-1245, 2013.

4. Schmiegel W, Reinacher-Schick A, Arnold D, Kubicka S, Freier W, Dietrich G, Geißler M, Hegewisch-Becker S, Tannapfel A, Pohl M, et al: Capecitabine/irinotecan or capecitabine/oxaliplatin in combination with bevacizumab is effective and safe as first-line therapy for metastatic colorectal cancer: A randomized phase II study of the AIO colorectal study group. Ann Oncol 24: $1580-1587,2013$
5. Bennouna J, Sastre J, Arnold D, Österlund P, Greil R, Van Cutsem E, von Moos R, Viéitez JM, Bouché O, Borg C, et al: Continuation of bevacizumab after first progression in metastatic colorectal cancer (ML18147): A randomised phase 3 trial. Lancet Oncol 14: 29-37, 2013.

6. Hamamoto Y, Yamaguchi T, Nishina T, Yamazaki K, Ura T, Nakajima T, Goto A, Shimada K, Nakayama N, Sakamoto J, et al: A phase I/II study of XELIRI plus bevacizumab as second-line chemotherapy for Japanese patients with metastatic colorectal cancer (BIX Study). Oncologist 19: 1131-1132, 2014.

7. Sakar B, Gumus M, Basaran M, Argon A, Ustuner Z, Ustaoglu MA, Saglam S, Guney N, Tenekeci AN and Aykan NF: XELOX followed by XELIRI or the reverse sequence in advanced colorectal cancer. Oncology 73: 298-304, 2007.

8. Lassere $\mathrm{Y}$ and Hoff P: Management of hand-foot syndrome in patients treated with capecitabine (Xeloda). Eur J Oncol Nurs 8 (Suppl 1): S31-S40, 2004.

9. Eisenhauer EA, Therasse P, Bogaerts J, Schwartz LH, Sargent D, Ford R, Dancey J, Arbuck S, Gwyther S, Mooney M, et al: New response evaluation criteria in solid tumours: Revised RECIST guideline (version 1.1). Eur J Cancer 45: 228-247, 2009.

10. Japanese translation of common terminology criteria for adverse events (CTCAE) and instructions and guidelines. Int J Clin Oncol 9 (Suppl 3): S1-S82, 2004 (In Japanese).

11. Balducci $L$ and Beghe C: The application of the principles of geriatrics to the management of the older person with cancer. Crit Rev Oncol Hematol 35: 147-154, 2000.

12. Cassidy J, Clarke S, Díaz-Rubio E, Scheithauer W, Figer A, Wong R, Koski S, Lichinitser M, Yang TS, Rivera F, et al: Randomized phase III study of capecitabine plus oxaliplatin compared with fluorouracil/folinic acid plus oxaliplatin as first-line therapy for metastatic colorectal cancer. J Clin Oncol 26: 2006-2012, 2008.

13. Mabro M, Louvet C, André T, Carola E, Gilles-Amar V, Artru P, Krulik M and de Gramont A; GERCOR: Bimonthly leucovorin, infusion 5-fluorouracil, hydroxyurea and irinotecan (FOLFIRI-2) for pretreated metastatic colorectal cancer. Am J Clin Oncol 26: 254-258, 2003

14. Mabro M, Artru P, André T, Flesch M, Maindrault-Goebel F, Landi B, Lledo G, Plantade A, Louvet C and de Gramont A: A phase II study of FOLFIRI-3 (double infusion of irinotecan combined with LV5FU) after FOLFOX in advanced colorectal cancer patients. Br J Cancer 94: 1287-1292, 2006.

15. Beretta GD, Petrelli F, Stinco S, Cabiddu M, Ghilardi M, Squadroni M, Borgonovo K and Barni S: FOLFIRI + bevacizumab as second-line therapy for metastatic colorectal cancer pretreated with oxaliplatin: A pooled analysis of published trials. Med Oncol 30: 486, 2013.

16. Suzuki K, Takaharu K, Muto Y, Ichida K, Fukui T, Takayama Y, Tsujinaka S, Sasaki J, Horie H, Kawamura YJ, et al: XELIRI regimen plus continuous treatment with bevacizumab is well-tolerated and effective in metastatic colorectal cancer patients in a second-line setting involving the sequential administration of XELOX and XELIRI. Mol Clin Oncol 2: 827-832, 2014.

17. Chu E, Haller D, Cartwright T, Twelves C, Cassidy J, Sun W, Saif MW, McKenna E7, Lee S and Schmoll HJ: Epidemiology and natural history of central venous access device use and infusion pump function in the NO16966 trial. Br J Cancer 110: 1438-1445, 2014.

18. Conroy T, Hebbar M, Bennouna J, Ducreux M, Ychou M,Llédo G, Adenis A, Faroux R, Rebischung C, Kockler L and Douillard JY: Quality-of-life findings from a randomised phase-III study of XELOX vs FOLFOX-6 in metastatic colorectal cancer. Br J Cancer 102: 59-67, 2010.

19. Perrocheau G, Bennouna J, Ducreux M, Hebbar M, Ychou M, Lledo G, Conroy T, Dominguez S, Faroux R, Florentin V and Douillard JY: Cost-minimisation analysis in first-line treatment of metastatic colorectal cancer in France: XELOX versus FOLFOX-6. Oncology 79: 174-180, 2010. 